\title{
Could Rice Yield Change Be Caused by Weather?
}

\section{-Empirical Analysis from Hainan, China}

\author{
Wen Yu1,2, Yu Wang1,2, Denghua Li1,2, Shiwei Xu' ${ }^{1,2}$, Ahmed Abdul-Gafar ${ }^{1,2}$ \\ ${ }^{1}$ Agricultural Information Institute, Chinese Academy of Agricultural Sciences, Beijing, China \\ ${ }^{2}$ Key Laboratory of Digital Agricultural Early-Warning Technology, Ministry of Agriculture, Beijing, China \\ Email: yuwen1969@263.net, yuwen@caas.cn, *403284815@qq.com, \\ lidenghua@caas.cn, abd.gafar1@icloud.com
}

Received 8 March 2016; accepted 23 April 2016; published 30 April 2016

\begin{abstract}
Data from 4 counties of Hainan Province of China from 1991-2012 was used to determine the weather impact on rice yields in both early and late rice seasons with multiple regression models. The results show there is normal weather environment for rice in the heading stage for early season rice in May and the milking stage for late season rice in November. For early season rice, more rain in April and June is better for rice to boot and milk, the average temperature has negative effect for the season rice yield ; for late season rice, the average temperature have positive effect for the difference between rice yield and the mean of total years but in seedling and booting stage; the rice yield difference between double season is compared and analyzed through the difference of meteorological factors, the results show that the precipitation gap in tillering stage has positive effect to rice yield increasing, but against in booting stage. The relative results should be use to forecast rice yield, and further provide the rice production guiding.
\end{abstract}

\section{Keywords}

Meteorological Factors, Rice Yield Change, Model, Hainan of China

\section{Introduction}

Scientists conducted research explaining relationship between climate and crop yield forecasting (Mikhail A. Semenov, et. al., 2012) [1]. Some scientists worked on the relationship between crop yield and climate (Nicholls N., 1997; David B Lobell and Gregory P Asner, 2003; Peng, S.,etc., 2004; Xu Shiwei, Yu Wen and etc., 2013; Xu S., Yu W., and etc., 2013) [2]-[6]; and also these articles referred above did not include more climate factors and disasters for regression estimation. In this article, precipitation, temperature, wind speed, sunshine will be included and also low temperature, extreme wind speed, floods, etc.. in addition, the monthly data help estimation the weather contribution in detail.

"Corresponding author. 
After the research, not only the yield change contributions by meteorological factors, but also the coefficients help crop yield changing forecasting.

The article is organized in the following parts: first part is introduction; 2nd part is about data and its description; 3rd part is the method, multiple regression models; part 4 is estimation analysis based on model results; and the last part is about conclusion and discussion.

\section{Data}

This article uses time series data, including early and late season rice yield, and meteorological data. Meteorological data is from China Meteorological Data Sharing Service System (CMDSSS); and rice yield data in local regions for Hainan Province is from Hainan Statistical Yearbooks.

Hainan province is an island located at the extreme south of China. It is located in $180^{\circ} 10^{\prime}-200^{\circ} 10^{\prime} \mathrm{N}$ and $1080^{\circ} 37^{\prime}-1110^{\circ} 03^{\prime} \mathrm{E}$ covering land area of about 35.4 thousand square kilometres and has maritime area of about 2 million square kilometers. 4 counties or cities were selected from 18 of Hainan Province, they are Qiongshan (north of Hainan, $19^{\circ} 32^{\prime}-20^{\circ} 05^{\prime} \mathrm{N}, 110^{\circ} 11^{\prime}-110^{\circ} 41^{\prime} \mathrm{E}$ ), Danzhou (northwestern Hainan, $19^{\circ} 11^{\prime}$ $19^{\circ} 52^{\prime} \mathrm{N}, 108^{\circ} 56^{\prime}-109^{\circ} 46^{\prime} \mathrm{E}$ ), Qiongzhong (Center of Hainan, $18^{\circ} 43^{\prime}-19^{\circ} 25^{\prime} \mathrm{N}, 109^{\circ} 31^{\prime}-110^{\circ} 09^{\prime} \mathrm{E}$ ) and Lingshui (southeastern Hainan, $18^{\circ} 22^{\prime}-18^{\circ} 47^{\prime} \mathrm{N}, 109^{\circ} 45^{\prime}-110^{\circ} 08^{\prime} \mathrm{E}$ ).

Rice is one of the major main crops in the region and mostly cultivated twice a year. According to the rice growth seasons, early season rice are often transplanted in February and harvest in June or earlier July; late season rice often transplants in July or earlier August and harvest in November. According to the disaster dataset about Hainan from CMDSSS, for early season rice, drought and clod are main constraints; but floods, heavy rains, typhoon and disease are major disasters for late season rice. The main meteorological index are in the following Table 1.

Like southern China, Hainan often plant double rice annually. In the above Figure 1, the yields of early season rice have significant increasing trend generally, but late season rice yield show no obvious trend.

Table 1. The average value of meteorological factors from 1991 to 2012 for selected station in Hainan of China.

\begin{tabular}{|c|c|c|c|c|c|c|c|c|c|c|c|c|c|}
\hline Weather (unit) & station & Jan & Feb & Mar & Apr & May & Jun & Jul & Aug & Sep & Oct & Nov & Dec \\
\hline precipitation & danxian & 6 & 8 & 15 & 27 & 76 & 68 & 78 & 114 & 112 & 74 & 29 & 14 \\
\hline \multirow[t]{4}{*}{$(0.1 \mathrm{~mm})$} & lingshui & 5 & 7 & 10 & 28 & 53 & 72 & 88 & 64 & 113 & 104 & 25 & 12 \\
\hline & qiongshan & 6 & 12 & 16 & 27 & 60 & 83 & 76 & 89 & 94 & 91 & 18 & 13 \\
\hline & qiongzhong & 11 & 15 & 17 & 37 & 83 & 60 & 73 & 103 & 131 & 142 & 64 & 29 \\
\hline & mean & 7 & 10 & 14 & 30 & 68 & 71 & 79 & 92 & 113 & 103 & 34 & 17 \\
\hline temperature & danxian & 177 & 196 & 224 & 257 & 272 & 283 & 281 & 273 & 262 & 246 & 219 & 187 \\
\hline \multirow[t]{4}{*}{$\left(0.1^{\circ} \mathrm{C}\right)$} & lingshui & 207 & 219 & 240 & 265 & 280 & 286 & 284 & 281 & 273 & 261 & 242 & 217 \\
\hline & qiongshan & 180 & 194 & 222 & 256 & 277 & 288 & 288 & 283 & 274 & 258 & 230 & 196 \\
\hline & qiongzhong & 174 & 193 & 219 & 248 & 264 & 273 & 272 & 265 & 254 & 236 & 211 & 182 \\
\hline & mean & 185 & 200 & 226 & 257 & 273 & 282 & 281 & 276 & 266 & 251 & 226 & 195 \\
\hline wind & danxian & 20 & 20 & 20 & 19 & 18 & 19 & 20 & 18 & 18 & 21 & 20 & 20 \\
\hline \multirow[t]{4}{*}{$(0.1 \mathrm{~m} / \mathrm{s})$} & lingshui & 23 & 21 & 21 & 19 & 17 & 17 & 17 & 17 & 20 & 27 & 28 & 28 \\
\hline & qiongshan & 26 & 26 & 29 & 29 & 25 & 24 & 24 & 21 & 22 & 27 & 27 & 27 \\
\hline & qiongzhong & 11 & 13 & 16 & 15 & 13 & 14 & 15 & 13 & 11 & 10 & 10 & 9 \\
\hline & mean & 20 & 20 & 21 & 21 & 18 & 18 & 19 & 17 & 18 & 21 & 21 & 21 \\
\hline sunshine & danxian & 38 & 44 & 49 & 57 & 64 & 67 & 70 & 64 & 50 & 51 & 44 & 34 \\
\hline \multirow[t]{4}{*}{$(0.1 \mathrm{~h})$} & lingshui & 52 & 51 & 51 & 63 & 70 & 67 & 70 & 67 & 55 & 57 & 53 & 48 \\
\hline & qiongshan & 28 & 33 & 39 & 52 & 64 & 67 & 74 & 68 & 55 & 53 & 41 & 32 \\
\hline & qiongzhong & 36 & 44 & 54 & 64 & 67 & 67 & 70 & 63 & 50 & 46 & 38 & 30 \\
\hline & mean & 39 & 43 & 48 & 59 & 66 & 67 & 71 & 65 & 53 & 52 & 44 & 36 \\
\hline
\end{tabular}




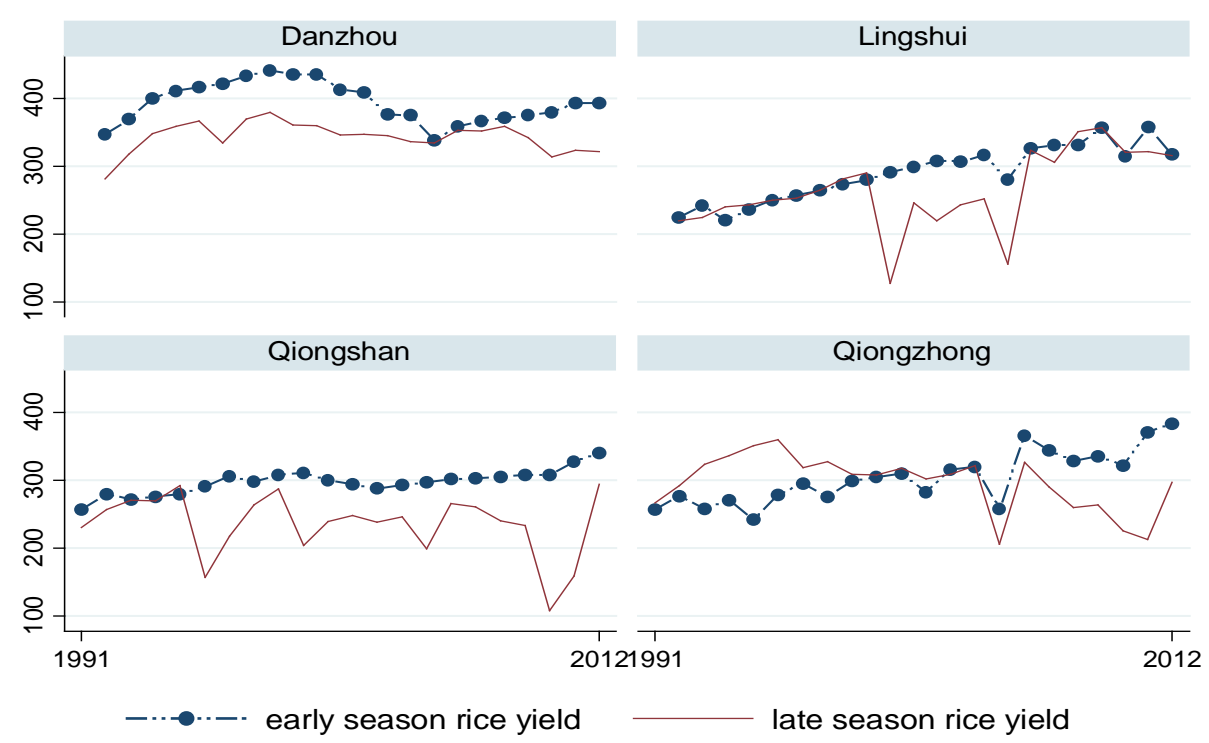

Figure 1. Season rice yield in Danzhou, Lingshui, Qiongshan and Qiongzhong of Hainan, China during 1991-2012.

\section{Method}

In order to estimate the relationship between rice yield and meteorological factors, the model considers precipitation, rain frequency per month, wind speed, the days of strong wind, average temperature, low temperature, sunshine and technological trend, which is denoted as T. In this article, the analysis will be going on by two methods.

\subsection{Independent Season Rice Yield Model}

The model in this article hypothesized that the climate or weather has the same effective to rice yield excluding regions.

Firstly, using the difference between season rice yield and average rice yield by the station group as dependent variable, this is estimated by empirical analysis with technology variable denoted as $\mathrm{T}$ and meteorological factor change (the difference between meteorological factor and its mean). The relative function is as in the following:

$$
\begin{aligned}
& \Delta \text { yield }=\text { constant }+\mathrm{T}+\sum\left(\alpha_{\mathrm{i}} * \Delta \text { rain }_{\mathrm{i}}+\beta_{\mathrm{i}} * \Delta \text { sunshine }_{\mathrm{i}}+\gamma_{\mathrm{i}} * \Delta \text { temp }_{\mathrm{i}}+\theta_{\mathrm{i}} * \Delta \text { wind }_{\mathrm{i}}\right. \\
& \left.+\mathrm{a}_{\mathrm{i}} * \Delta \text { raintimes }_{\mathrm{i}}+\mathrm{b}_{\mathrm{i}} * \Delta \text { lowtemp }_{\mathrm{i}}+\mathrm{c}_{\mathrm{i}} * \Delta \text { windtimes }_{\mathrm{i}}\right)
\end{aligned}
$$

And the relative variables are in the Table 2.

\subsection{Comparative Season Rice Yield Model}

Secondly, using the difference between early season and late season rice yield as dependent variable, as well as the independent variable by the difference between double season meteorological factors (the difference between meteorological factors during the same rice growing stage), the relative function is as in the following:

$$
\begin{aligned}
& \text { d_yield }=\text { constant }+\mathrm{T}+\sum\left(\alpha_{\mathrm{i}} * \mathrm{~d} \_ \text {rain }{ }_{\mathrm{i}}+\beta_{\mathrm{i}} * \mathrm{~d} \_ \text {sunshine }_{\mathrm{i}}+\gamma_{\mathrm{i}} * \mathrm{~d} \_ \text {temp } \mathrm{i}_{\mathrm{i}}+\theta_{\mathrm{i}} * \mathrm{~d} \_ \text {wind }_{\mathrm{i}}\right.
\end{aligned}
$$

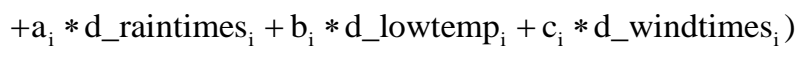

Apart from Table 2, all variables in Function (2) is the difference in the same life cycles between early season and late season rice; for example, $d \_y i e l d$ is the difference between double season yield; and the d_rain1 denotes the precipitation difference in seedling stage for double season rice; i, from 1 to 5 , denotes rice lifecycle, including stage of sowing and seedling, stage of transplanting and green turning, tillering stage, booting stage, heading stage, stage of milking and ripening, separately. 
Table 2. Variables and their description.

\begin{tabular}{|c|c|}
\hline variable & denotation \\
\hline$\Delta$ yield & rice yield in early season or late season, unit: $\mathrm{kg} / \mathrm{mu}, 1 \mathrm{mu}=1 / 15$ ha or $0.06667 \mathrm{ha}$ \\
\hline $\mathrm{T}$ & T is technological variable for rice yield caused by seed, management and ect. Progress, 1991 is the based year \\
\hline$\Delta$ rain_i & $\begin{array}{l}\text { Difference between current precipitation and average precipitation in the ith month, for example, } \\
\text { there are } 5 \text { rainy days in January } 1991 \text {, but there are } 4 \text { rainy days averagely in January from } 1991 \text { to 2012, } \\
\text { then the } \Delta \text { rain } 1 \text { in } 1991 \text { is } 1(=5-4) \text {, unit: } 0.1 \mathrm{~mm}\end{array}$ \\
\hline$\Delta$ raintimes_i & Difference between current rainy days and average rainy days in the ith month \\
\hline$\Delta$ sunshine_i & Difference between current and average solar radiation duration in the ith month, unit: 0.1 hours/day \\
\hline$\Delta$ temp_i & Difference between current and average temperature per day in the ith month, unit: 0.1 centigrade \\
\hline$\Delta$ lowtemp_i & Difference between current and average low temperature per day in the ith month, unit: 0.1 centigrade \\
\hline$\Delta$ wind_i & Difference between current and average wind speed per day in the ith month, unit: $0.1 \mathrm{~m} / \mathrm{s}$ \\
\hline$\Delta$ windtimes_i & Difference between current and average days when wind speed is over $20 \mathrm{~m} / \mathrm{s}$ in the ith month, unit: $0.1 \mathrm{~m} / \mathrm{s}$ \\
\hline i & $\begin{array}{l}\text { January to December orderly with number } 1,2, \ldots, 12 \text { respectively; among the early season, } \\
\qquad \mathrm{i}=1 \text { to } 6 \text {; in late season for rice, the } \mathrm{I} \text { is from } 6 \text { to } 11\end{array}$ \\
\hline _Istation_1 & Station = Danzhou \\
\hline _Istation_2 & Station $=$ lingshui \\
\hline _Istation_3 & Station = qiongshan \\
\hline _Istation_4 & Station = qiongzhong \\
\hline
\end{tabular}

\section{Results}

The meteorological units in this research are: rain or precipitation $0.1 \mathrm{~mm}$; wind speed $0.1 \mathrm{~m} / \mathrm{s}$; temperature $0.1^{\circ} \mathrm{C}$; Solar radiation $0.1 \mathrm{~h}$. it is the same units in the Table 4 as in the following.

From the results in the Table 3, F-Value show that the model could be appropriate; and the R-squared value instructs the independent variables could explain the dependent-yield more than $50 \%$.

Early season rice: January is the sowing period, in the stage, rice begins emergence and seedling. Comparing with average yield, the yield changing is caused by average temperature and low temperature. Increasing low-temperature has positive effect for yield but average temperature has negative effect. It is the period for young plant to transplant to field, and it will turn green in February. the higher temperature is not good, and more wind will brings cool air benefits seedlings; In March, rice plant is in the tillering stage, rice likes more cloudy days to tiller, which means little higher temperature but less solar radiation; In April, after tillering, the booting rice require more water, in this stage, low temperature would hard the plant, higher average temperature is not suitable for the plant growth; In May, the normal climate environment is adapted for rice heading; in June, the rainy with higher average temperature is good for rice to filling milk.

Late season rice: in June or early July, after harvesting early season rice, young plant will soon be transplanted into the field. So the sowing and emergence and seedling should be prepared in June, when temperature is higher, more rain and more wind benefits for the yield increasing; in July, the plant is at its weak state, the rice is turning green, higher temperature and strong wind is not good for the plant development, but more sunshine is better; in August, rice is at its tillering stage, wind and rain is suitable for young plant but continuous rain and low temperature will be harmful to young tillering plant; during booting stage in September, more rainy and windy days are not good for rice but low temperature and sunshine increasing benefit for the plant, anyway average temperature decreasing is better; and in October, it is in the heading stage, cold, speed wind, sunny weather is not better but higher average temperature and more windy benefit heading for rice; the weather in November is appropriated for rice milking and ripening.

In the second step, the difference between early season and late season rice yield is estimated through $\mathrm{T}$ variable (technology and management) meteorological factors. From the results in Table 4 (the authors use the 
Table 3. Analysis of double season rice yield change contributed by being changed climate in growing stages from 1991 to 2012.

\begin{tabular}{|c|c|c|c|c|c|c|c|c|}
\hline \multirow{2}{*}{ stage } & \multicolumn{4}{|c|}{ Early season rice } & \multicolumn{4}{|c|}{ Late season rice } \\
\hline & month & varialble & Coef. & t-Value & month & variable & Coef. & $t$-Value \\
\hline & Jan & $\Delta$ rain_01 & & & Jun & $\Delta$ rain_06 & 0.30 & 3.06 \\
\hline sowing & & $\Delta$ raintimes_01 & & & & $\Delta$ raintimes_06 & & \\
\hline emergence & & $\Delta$ temp_01 & -1.84 & -2.86 & & $\Delta$ temp_06 & 2.89 & 2.65 \\
\hline \multirow[t]{5}{*}{ seedling } & & Alowtemp_01 & 1.96 & 3.24 & & Alowtemp_06 & & \\
\hline & & $\Delta$ wind_01 & & & & $\Delta$ wind_06 & & \\
\hline & & $\Delta$ windtimes_01 & & & & $\Delta$ windtimes_06 & 21.07 & 1.89 \\
\hline & & $\Delta$ sunshine_01 & & & & $\Delta$ sunshine_06 & & \\
\hline & Feb & $\Delta$ rain_02 & & & Jul & $\Delta$ rain_07 & & \\
\hline transplanting & & $\Delta$ raintimes_02 & & & & $\Delta$ raintimes_07 & & \\
\hline \multirow[t]{6}{*}{ Greenturn } & & $\Delta$ temp_02 & -0.53 & -3.06 & & $\Delta$ temp_07 & -2.07 & -1.77 \\
\hline & & Alowtemp_02 & & & & Alowtemp_07 & & \\
\hline & & $\Delta$ wind_02 & 1.31 & 2.81 & & $\Delta$ wind_07 & -2.98 & -2.32 \\
\hline & & $\Delta$ windtimes_02 & & & & $\Delta$ windtimes_07 & & \\
\hline & & $\Delta$ sunshine_02 & & & & $\Delta$ sunshine_07 & 0.67 & 1.61 \\
\hline & Mar & $\Delta$ rain_03 & & & Aug & $\Delta$ rain_08 & & \\
\hline \multirow[t]{7}{*}{ tillering } & & $\Delta$ raintimes_03 & & & & $\Delta$ raintimes_08 & -3.09 & -2.52 \\
\hline & & $\Delta$ temp_03 & 0.99 & 2.76 & & $\Delta$ temp_08 & 3.67 & 1.93 \\
\hline & & Alowtemp_03 & & & & Alowtemp_08 & -4.46 & -2.45 \\
\hline & & $\Delta$ wind_03 & & & & $\Delta$ wind_08 & 6.58 & 4.37 \\
\hline & & $\Delta$ windtimes_03 & & & & $\Delta$ windtimes_08 & & \\
\hline & & $\Delta$ sunshine_03 & -1.51 & -4.03 & & $\Delta$ sunshine_08 & -0.98 & -1.72 \\
\hline & Apr & $\Delta$ rain_04 & 0.28 & 2.25 & Sep & $\Delta$ rain_09 & & \\
\hline \multirow[t]{7}{*}{ booting } & & $\Delta$ raintimes_04 & & & & $\Delta$ raintimes_09 & -3.65 & -3.20 \\
\hline & & $\Delta$ temp_04 & -1.35 & -2.04 & & $\Delta$ temp_09 & -6.12 & -3.28 \\
\hline & & Slowtemp_04 & 1.70 & 2.35 & & Alowtemp_09 & 6.82 & 3.98 \\
\hline & & $\Delta$ wind_04 & & & & $\Delta$ wind_09 & & \\
\hline & & $\Delta$ windtimes_04 & & & & $\Delta$ windtimes_09 & -15.39 & -2.82 \\
\hline & & $\Delta$ sunshine_04 & & & & $\Delta$ sunshine_09 & 0.99 & 1.80 \\
\hline & May & $\Delta$ rain_05 & & & Oct & $\Delta$ rain_10 & & \\
\hline \multirow{6}{*}{$\begin{array}{l}\text { heading } \\
\text { milking }\end{array}$} & & $\Delta$ raintimes_05 & & & & $\Delta$ raintimes_10 & & \\
\hline & & $\Delta$ temp_05 & & & & $\Delta$ temp_10 & 11.36 & 5.86 \\
\hline & & Alowtemp_05 & & & & $\Delta$ lowtemp_10 & -8.77 & -5.83 \\
\hline & & $\Delta$ wind_05 & & & & $\Delta$ wind_10 & -3.10 & -3.31 \\
\hline & & $\Delta$ windtimes_05 & & & & $\Delta$ windtimes_10 & 37.38 & 2.61 \\
\hline & & $\Delta$ sunshine_05 & & & & $\Delta$ sunshine $\_10$ & -3.20 & -5.89 \\
\hline
\end{tabular}




\section{Continued}

\begin{tabular}{|c|c|c|c|c|c|c|c|c|}
\hline \multirow{12}{*}{ ripening } & Jun & $\Delta$ rain_06 & 0.15 & 1.73 & Nov & $\Delta$ rain_11 & & \\
\hline & & $\Delta$ raintimes_06 & & & & $\Delta$ raintimes & & \\
\hline & & $\Delta$ temp_06 & 1.25 & 2.04 & & $\Delta$ temp_1 & & \\
\hline & & $\Delta$ lowtemp_06 & & & & $\Delta$ lowtemp & & \\
\hline & & $\Delta$ wind_06 & & & & $\Delta$ wind_1 & & \\
\hline & & $\Delta$ windtimes_06 & & & & $\Delta$ windtimes & & \\
\hline & & $\Delta$ sunshine_06 & & & & $\Delta$ sunshine & & \\
\hline & & _cons & -0.12 & -0.05 & & _cons & 0.77 & 0.26 \\
\hline & & No. & bs $=88$ & & & & $\mathrm{~s}=8 \varepsilon$ & \\
\hline & & & $=7.8$ & & & & $=5.13$ & \\
\hline & & R-sq & $\mathrm{d}=0.53$ & & & & $I=0.6$ & \\
\hline & & Adj R- & ared $=0$. & & & & $\mathrm{ed}=0$ & \\
\hline
\end{tabular}

Table 4. Analysis on the difference between early season and late season rice yield.

\begin{tabular}{|c|c|c|c|c|}
\hline stage & variables & Coef. & $t$ value & $\mathrm{P}>\mathrm{t}$ \\
\hline & $\mathrm{T}$ & 2.92 & 3.9 & 0 \\
\hline \multirow[t]{2}{*}{ Seedling } & d_raintimes_01 & 1.73 & 2.26 & 0.027 \\
\hline & d_lowtemp_01 & 1.04 & 2.94 & 0.004 \\
\hline \multirow[t]{3}{*}{ Tillering } & d_temp_03 & -2.55 & -2.99 & 0.004 \\
\hline & d_rain_03 & 0.37 & 3.46 & 0.001 \\
\hline & d_lowtemp_03 & 2.70 & 2.54 & 0.013 \\
\hline Booting & d_rain_04 & -0.15 & -2.49 & 0.015 \\
\hline \multirow[t]{3}{*}{ Heading } & d_sunshine_05 & -1.38 & -3.33 & 0.001 \\
\hline & d_lowtemp_05 & -4.98 & -4.05 & 0 \\
\hline & d_temp_05 & 6.10 & 4.41 & 0 \\
\hline \multirow[t]{10}{*}{ milking } & d_wind_06 & -2.16 & -2.49 & 0.015 \\
\hline & d_lowtemp_06 & 0.64 & 1.47 & 0.146 \\
\hline & _Istation_2 & -59.40 & -3.72 & 0 \\
\hline & _Istation_3 & & & \\
\hline & _Istation_4 & -55.23 & -4.43 & 0 \\
\hline & _cons & 102.04 & 2.34 & 0.022 \\
\hline & \multicolumn{2}{|c|}{ Number of obs $=88$} & & \\
\hline & \multicolumn{2}{|c|}{$F(14,73)=8.15$} & & \\
\hline & \multicolumn{2}{|c|}{ R-squared $=0.61$} & & \\
\hline & \multicolumn{2}{|c|}{ AdjR-squared $=0.54$} & & \\
\hline
\end{tabular}

Considering the region difference, Danzhou and Qiongshan have no significant difference, Lingshui and Qiongzhou have obvious difference from Danzhou county. 
stepwise regression, the significant variables could only be kept), F-value and R-square show that the model has good fitting degree.

Due to the progress of technology and management, the early season rice yield has obvious increasing; the differences from meteorological factors have significant effects to the yield difference. In seedling stage, more rainy days and higher low-temperature (the lowest temperature averagely in the month) lead to the yield difference; during tillering stage, the difference increasing among precipitation and low-temperature has positive effect but average temperature has negative effect; in booting stage, the increasing difference for precipitation will decrease the yield change; during heading stage, the difference of sunshine and low-temperature have negative effect for the yield change but average temperature; in the milking stage, the gap of low-temperature will decrease the difference of rice yield but low-temperature increase the change.

\section{Conclusions and Discussion}

This article analyzes the change of season rice yield from two directions. Firstly, the authors discovers the relationship between season rice yield change from average level and the change of meteorological factors; secondly, comparing the yield change between early season and late season rice yield.

The empirical models could explain the yield change from the meteorological factors, but ignore the other material factors such as fertilizer, labor, and irrigation ect..

From the coefficients and the meteorological value, the rice yield change could be forecasted and the difference of rice yield also could be forecasted.

\section{Acknowledgements}

This paper was supported by the CAAS Science and Technology Innovation Project (number: CAAS-ASTIP2016-AII), founded by Chinese Academy of Agricultural Sciences and Technology.

\section{References}

[1] Semenov, M.A., Mitchell, R.A.C., Whitmore, A.P., Hawkesford, M.J., Parry, M.A.J. and Shewry, P.R. Shortcomings in Wheat Yield Predictions. Nature Climate Change, 2, 380-382. http://dx.doi.org/10.1038/nclimate1511

[2] Nicholls, N. (1997) Increased Australian Wheat Yield Due to Recent Climate Trends. Nature, 387, 484-485. http://dx.doi.org/10.1038/387484a0

[3] Lobell, D.B. and Asner, G.P. (2003) Climate and Management Contributions to Recent Trends in US Agricultural Yields. Science, 299, 1032. http://dx.doi.org/10.1126/science.1077838

[4] Peng, S., Huang, J., Sheehy, J.E., Laza, R.C., Visperas, R.M., Zhong, X., Centeno, G.S., Khush, G.S. and Cassman, K.G. (2004) Rice Yields Decline with Higher Night Temperature from Global Warming. Proceedings of the National Academy of Sciences (PNAS in USA), 101, 9971-9975. http://dx.doi.org/10.1073/pnas.0403720101

[5] Xu, S.W., Yu, W., Liu, S.Y., Zhang, S. and Wang, Y. (2013) The Impact of Meteorological Factors on the Winter Wheat Yield-The Case from Weishan County, Shandong Province. Journal of Agriculture, 10, 45-51.

[6] Xu, S., Yu, W., Liu, S., Ahmed, A. and Wang, Y. (2013) Meteorological Impact on the Winter Wheat Yield in Weishan, China. Journal of Applied Sciences, 13, 2740-2743. http://dx.doi.org/10.3923/jas.2013.2740.2743 